Research Paper

\title{
Enhanced basal tension in isolated rat tracheal smooth muscle stimulated by electric field stimulation under low temperature
}

\author{
Hsing-Won Wang1,2,3, Pin-Zhir Chao' ${ }^{1}$ Fei-Peng Lee ${ }^{1 凶}$ \\ 1. The Graduate Institute of Clinical Medicine and Department of Otolaryngology, College of Medicine, Taipei Medical University-Shuang Ho Hospital, \\ Taipei, Taiwan, Republic of China \\ 2. Department of Preventive and Community Medicine, College of Medicine, Taipei Medical University-Shuang Ho Hospital, Taipei, Taiwan, Republic of \\ China \\ 3. Department of Otolaryngology-Head and Neck Surgery, Tri-Service General Hospital, National Defense Medical Center, Taipei, Taiwan, Republic of China \\ $\triangle$ Corresponding author: Fei-Peng Lee, Department of Otolaryngology, Taipei Medical University-Shuang Ho Hospital, Taipei, Taiwan. +886-2-22490088 ext \\ 2902, Fax: +886-2-66007866 E-mail: fplee@tmu.edu.tw \\ (c) Ivyspring International Publisher. This is an open access article distributed under the terms of the Creative Commons Attribution (CC BY-NC) license \\ (https://creativecommons.org/licenses/by-nc/4.0/). See http://ivyspring.com/terms for full terms and conditions.
}

Received: 2018.06.01; Accepted: 2018.09.10; Published: 2018.10.20

\begin{abstract}
Exposure to cold causes cutaneous vasoconstriction to reduce body heat loss, while the airway warms up the inspired cold air, thus suggesting that cooling might evoke a response in tracheal smooth muscle different from that in cutaneous blood vessels. The aim of this study was to evaluate the effect of temperature on isolated rat trachea, with or without electric field stimulation (EFS). Tissue bath for isolated trachea was used. An in vitro isometric contraction of trachea from healthy male Sprague-Dawley rat (body weight: $\geq 200 \mathrm{~g}$ ) was continuously recorded. Tension in strips of rat trachea that were untreated and treated with EFS, was continuously recorded in stepwise manner at temperatures varying from $37^{\circ} \mathrm{C}$ to $7{ }^{\circ} \mathrm{C}$ or from $7{ }^{\circ} \mathrm{C}$ to $37^{\circ} \mathrm{C}$. Results indicated that descent and re-ascent of temperature produced temperature-dependent tension changes. Basal tension of the trachea decreased when temperature was reduced if EFS was not applied. EFS-induced spike contraction decreased when temperature was reduced, while basal tension increased at the same time. We concluded that low temperature induced rapid and reproducible contraction in isolated rat tracheal strip only if EFS was applied. Increasing temperature reduced basal tension and enhanced EFS-induced spike contraction of the trachea at the same time.
\end{abstract}

Key words: Trachea, smooth muscle, low temperature, in vitro study

\section{Introduction}

The trachea is a complex organ that plays a vital role in airway protection and hygiene maintenance. It contains cartilage, mucosa, nerves, vessels, and muscles. Posterior parts of the trachea are filled with smooth muscle fibers. Both trachea and tongue help regulate body temperature [1]. Some tissues such as skin, hair, and nasal mucosa also play an important role in body temperature regulation [2]. It was demonstrated that rapid cooling of ovine tracheal and bronchiolar smooth muscles induced contractile responses, which were inversely proportional to temperature and not epithelium-dependent [3]. However, the mechanism of cold-induced tracheal constriction with electric field stimulation (EFS) has not been well explored. During EFS, which was thought to involve nerve activity, the response of tracheal smooth muscle to low temperature might be different. The present study aimed to determine the direct effect of cooling on isolated rat tracheal smooth muscle and analyze the role of EFS in the mechanisms involved. When temperature changes, both trachea and airway patency are affected. This study established an isolated trachea model and evaluated the effect of low temperature on isolated rat trachea strip. The influences of temperature on basal tension and EFS-induced spike contraction of trachea were 
investigated.

\section{Materials and Methods}

\section{Tissue preparation}

All chemical reagents were obtained from Sigma (St. Louis, MO, USA). Twenty-four healthy male Sprague-Dawley rats (body weight: $\geq 200 \mathrm{~g}$ ) were humanely killed by $\mathrm{CO}_{2}$ gas asphyxiating, and two pieces of trachea ( $\sim 5 \mathrm{~mm}$ in length) were removed from each rat. This study was approved by an animal experiment review board (LAC-2017-0036). The tracheal specimen was mounted using two steel plates and submersed in a $30-\mathrm{ml}$ muscle bath at $37^{\circ} \mathrm{C}$ as previously reported $[4,5]$. Briefly, the bath was filled with $30 \mathrm{ml}$ Krebs solution consisting of $(\mathrm{mmol} / \mathrm{L})$ $\mathrm{KCl}, 4.7 ; \mathrm{NaCl}, 118 ; \mathrm{MgSO}_{4} \cdot 7 \mathrm{H}_{2} \mathrm{O}, 1.2 ; \mathrm{CaCl}_{2}, 2.5$; $\mathrm{KH}_{2} \mathrm{PO}_{4}, 1.2 ; \mathrm{NaHCO}_{3}, 25.0$; and glucose, 11.0. The upper side of the tracheal strip was attached to a Grass FT-03 force displacement transducer (AstroMed, West Warwick, RI, USA) using a steel plate and a 3-0 silk ligature. The lower side of the strip was fixed to a steel plate attached to the bath. A passive tension of $0.3 \mathrm{~g}$ was applied to the strips and subsequent changes in tension were continuously recorded using DigiLog for windows V5.10.7 software analysis (Singa Technology, Taiwan). Preliminary tests showed that the tracheal strip immersed in the bath solution used for subsequent experiments did not contract when basal tension was applied. Before temperature assays were conducted, isolated tracheas were equilibrated in the bath solution for 15-30 $\mathrm{min}$ at $37{ }^{\circ} \mathrm{C}$, during which continuous aeration with a mixture of $95 \% \mathrm{O}_{2}$ and $5 \% \mathrm{CO}_{2}$ was applied.

Tissue temperature control was performed using a thermo-controlled water pump (Firstek Scientific, Taipei, Taiwan) that circulates water through water-jacketed glass chambers. The rapid decrease or increase in temperature was achieved through addition of an adequate amount of ice or $74{ }^{\circ} \mathrm{C}$ water into the water reservoir. Approximately 2-3 minutes were required to reach each temperature. Then every cooling period was maintained until peak response of the sample leveled off, after which the temperature was changed to the next level. A thermometer placed within the water bath confirmed the actual temperature of the preparation at any given time. In addition, the effect of stepwise temperature changes $\left(37^{\circ} \mathrm{C}, 25^{\circ} \mathrm{C}, 15^{\circ} \mathrm{C}\right.$ and $\left.7{ }^{\circ} \mathrm{C}\right)$ was also evaluated. In each experiment, one untreated strip served as a control.

\section{Decellularization method}

The extracellular matrix (ECM) of isolated trachea was made according to a method described earlier [6]. The specimen was placed in a detergent solution (sodium dodecyl sulfate, SDS, $0.1 \%$ ) in a 37 ${ }^{\circ} \mathrm{C}$ shaking water bath for 15 hours to remove the cellular components. The isolated trachea was then washed with agitation 5 times in phosphate-buffered saline for periods of 10 minutes each and then used for isometric tension study.

\section{Electrical field stimulation}

EFS $(5 \mathrm{~Hz}, 5 \mathrm{~ms}$ pulse duration, at a voltage of 50 $\mathrm{V}$, trains of stimulation for 5 seconds) was applied to the trachea strip with two wire electrodes placed parallel to the trachea strip and connected to a direct-current stimulator (Grass S44, Quincy, MA, USA). An interval of 2 minutes was imposed between each stimulation period to allow for recovery from the response. Stimulation was continuously applied to the trachea strip at $37^{\circ} \mathrm{C}$. Then, bath temperature was decreased to $7{ }^{\circ} \mathrm{C}$. Once the basal tension of the trachea strip stabilized at $7{ }^{\circ} \mathrm{C}$, bath temperature was increased to $37^{\circ} \mathrm{C}$.

\section{Statistical analysis}

Results were expressed as mean \pm SEM. Student's t-test was used for statistical evaluation. The difference was considered significant at $\mathrm{P}<0.05$.

\section{Results}

The amount of relaxation or contraction of tracheal strips was easily estimated from the tension applied to the transducer. With or without decellularization, decrease in temperature (from $37^{\circ} \mathrm{C}$ to $7^{\circ} \mathrm{C}$ ) reduced basal tension in the tracheal strip; while increase in temperature (from $7^{\circ} \mathrm{C}$ to $37^{\circ} \mathrm{C}$ ) elevated the tension (Figs. 1, 2). For tracheal strips without decellularization, basal tension was $0.33 \pm$ $0.11 \mathrm{~g}(\mathrm{n}=6)$ at $37^{\circ} \mathrm{C}$ and $0.18 \pm 0.04 \mathrm{~g}(\mathrm{n}=6)$ at $7{ }^{\circ} \mathrm{C}$ (Figs. 1, 2), indicating significant reduction in basal tracheal tension when temperature dropped from 37 ${ }^{\circ} \mathrm{C}$ to $7{ }^{\circ} \mathrm{C}(\mathrm{P}<0.01)$. The effect of stepwise temperature changes $\left(25^{\circ} \mathrm{C}, 15^{\circ} \mathrm{C}\right.$ and $\left.7^{\circ} \mathrm{C}\right)$ on basal tension in tracheal strips without EFS showed $57.8 \% \pm$ $4.3 \%, 42.5 \% \pm 4.9 \%$ and $27.5 \% \pm 5.6 \%$ of contraction respectively as compared with that at $37^{\circ} \mathrm{C}$ calculated as $100 \%$ (Fig. 3). The spike contraction induced by EFS was decreased when bath temperature was reduced (Figs. 1, 4). Tension peaks of the trachea evoked by EFS were $0.28 \pm 0.01 \mathrm{~g}$ at $37^{\circ} \mathrm{C}(\mathrm{n}=6)$ and $0.08 \pm 0.01 \mathrm{~g}$ $(\mathrm{n}=6)$ at $7{ }^{\circ} \mathrm{C}$ (Figs. 1, 3). The EFS-evoked tension peaks of the trachea was $100 \%$ and $35 \% \pm 12.8 \%$ of the control values at $37^{\circ} \mathrm{C}$ and $7{ }^{\circ} \mathrm{C}$, respectively (Fig. 4), revealing statistically significant difference in peak tension among the specimens treated with EFS at 37 ${ }^{\circ} \mathrm{C}$ and $7^{\circ} \mathrm{C}$. The tension peaks of the trachea evoked by EFS at $37^{\circ} \mathrm{C}$ were significantly higher than that at 7 

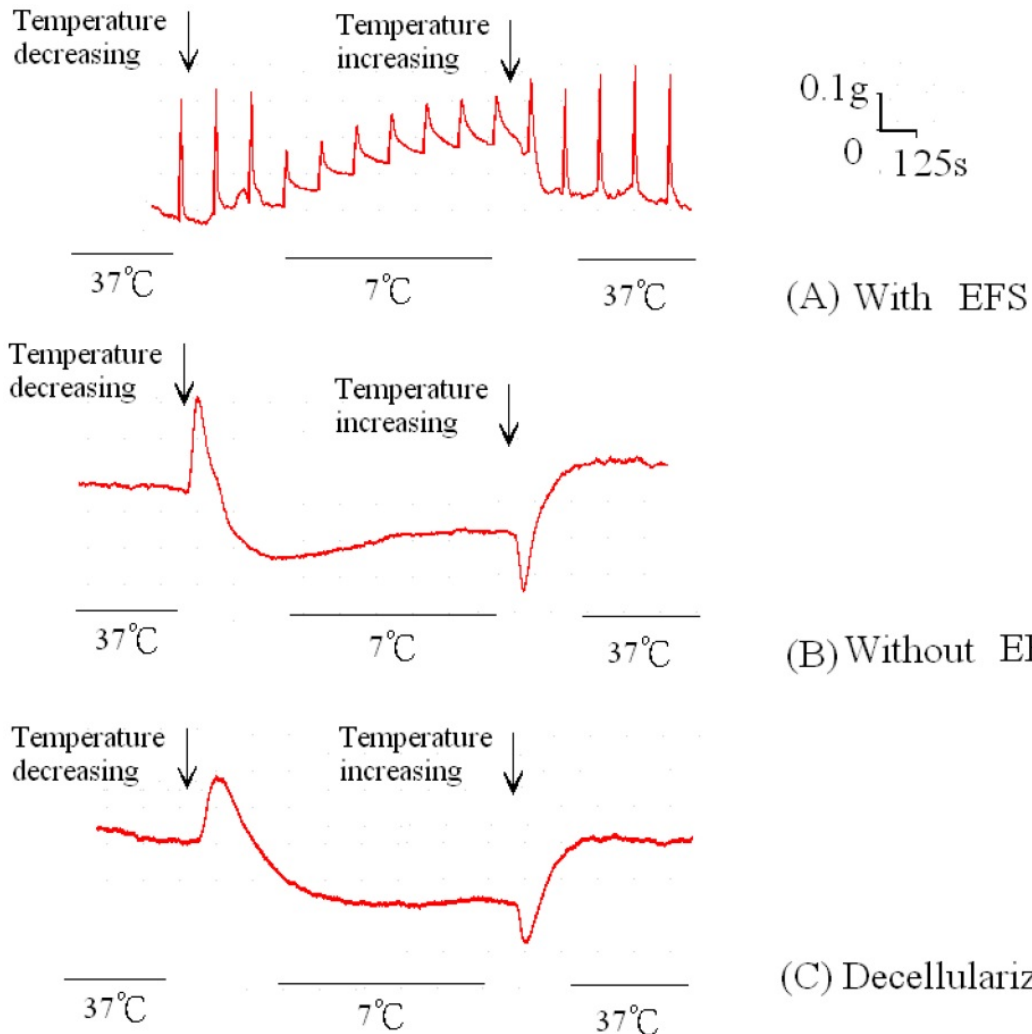

Figure 1. Original recording of basal tension of trachea strips at different temperatures with or without EFS. (Upper) Decrease in temperature enhanced basal tension and reduced EFS-induced spikes contraction of tracheal strip. (Middle) Without EFS, temperature decrease lessened basal tension. An initial spike under changing temperature was also noted. (Bottom) Decellularized strip showed a reaction to temperature changes similar to that of tracheal strip without EFS treatment. EFS (electrical field stimulation).

${ }^{\circ} \mathrm{C}(\mathrm{P}<0.01)$. During EFS test, basal tension also increased when temperature was changed from $37^{\circ} \mathrm{C}$ to $7^{\circ} \mathrm{C}$. The basal-tracheal tension was $0.31 \pm 0.02 \mathrm{~g}$ (n $=6)$ at $37^{\circ} \mathrm{C}$ and $0.40 \pm 0.07 \mathrm{~g}(\mathrm{n}=6)$ at $7^{\circ} \mathrm{C}$ (Figs. 1, 2), indicating significant increase when temperature was changed from $37^{\circ} \mathrm{C}$ to $7{ }^{\circ} \mathrm{C}(\mathrm{P}<0.01)$. Decellularized tracheal strips showed no response to EFS. Descent or re-ascent of temperature inducing a single initial spike reaction of tracheal strip was also noted.

\section{Discussion}

The contractile response observed in this study was probably an aggregate of the responses of various types of tracheal smooth muscle. It was not easy to obtain human tissue for similar studies. The effect of temperature on isolated human trachea still needs further investigation. In vitro single muscle fiber study of the tracheal strip is not yet possible at the present time. This research was an in vitro study; hence, there were reservations as to its comparability with an in vivo situation in humans. In the in vivo situation, the response might be much more complicated than that in the in vitro situation.

In dogs, the tongue serves as an essential heat regulator. When the body temperature was increased, vasodilatation was observed to increase blood flow to the tongue [2]. This study observed that when the ambient temperature was lower than body temperature, basal tension of the trachea without EFS was decreased, implying that the content of muscle of the trachea may be relaxed. Relaxed human airways under cooling had been proved by an in vitro study [7]. The present result concurred with such finding. The reason for this phenomenon is still unclear and needs additional studies for clarification. It has been reported that decrease in bath temperature from 37 to 20 ${ }^{\circ} \mathrm{C}$ (cooling) had no effect on basal tone [8]. However, isolated tracheas of sheep, dogs, and rats developed an enhanced contractile response when the temperature of the isolated organ is lowered from 37 to 18-20 ${ }^{\circ} \mathrm{C}$ [9-11]. Enhanced low-temperature-

dependent contractile response is observed only after a low-frequency stimulation range $(0.1-20 \mathrm{~Hz})$, that is very close to the frequency of vagal stimuli required for inducing bronchoconstriction in vivo [11]. The discrepancy might be due to different species or methodologies used. In our previous study, cooling (to $30-10^{\circ} \mathrm{C}$ ) decreased the basal tension of turbinate mucosa [2], which might be attributed to structural factor of the turbinate mucosa rather than vascular response. Structural factor of the tracheal smooth muscle response to low temperature was quite similar to that of turbinate mucosa in this study. Structural factor response could be proved by the decellularized trachea showing the same reaction. Further studies are needed to elucidate these discrepancies.

EFS-induced spike contraction of the tracheal strip was thought to originate from parasympathetic innervation stimulation. Pre-treatment with $3 \times 10^{-5} \mathrm{M}$ atropine in EFS test for cold temperature changes showed total inhibition of spike contraction and increase in basal tension (data not shown). It was compatible with previous findings that the effects of electrical stimulation could be obliterated by atropine $[12,13]$. Therefore, reduction in EFS-induced spike 
contraction of the tracheal strip under decrease in temperature suggests reduction in parasympathetic functions with decreasing temperature. Menthol, a cold receptor agonist, inhibiting parasympathetic function of tracheal smooth muscle was identified in our previous report [5]. If basal tracheal tension with EFS was enhanced under temperature decrease, the airway patency could be decreased as well. Exposure of asthma patients to low temperature is linked to the onset and worsening of asthma [14]. The current result concurred with such finding. The initial spike contraction induced by cold Krebs solution could be explained by the common physical property as thermal contraction. This could be proved by similar reactions obtained by the same experiment applied to decellularized tracheal strip. Acute exposure to cold temperature can affect the respiratory system of those exposed to extreme weather and induces asthma in asthmatic patients [15]. However, cooling relaxed human airways in vitro and reduced responsiveness to methacholine and histamine [7]. These experimental findings contrary to the present results may explain, at least in part, the discrepant reports between cooling of tracheal mucosa and asthma attack. The acute increase in tension by decreasing the temperature could involve stimulation of the parasympathetic innervation and the late decrease in tension could be related to an inhibition of kinases, such as myosin light-chain kinase, protein kinase $\mathrm{C}$ or Rho kinase involved in the smooth muscle contraction [16, 17]. Phenomena observed in this study are of interest and merit further study for clarification.

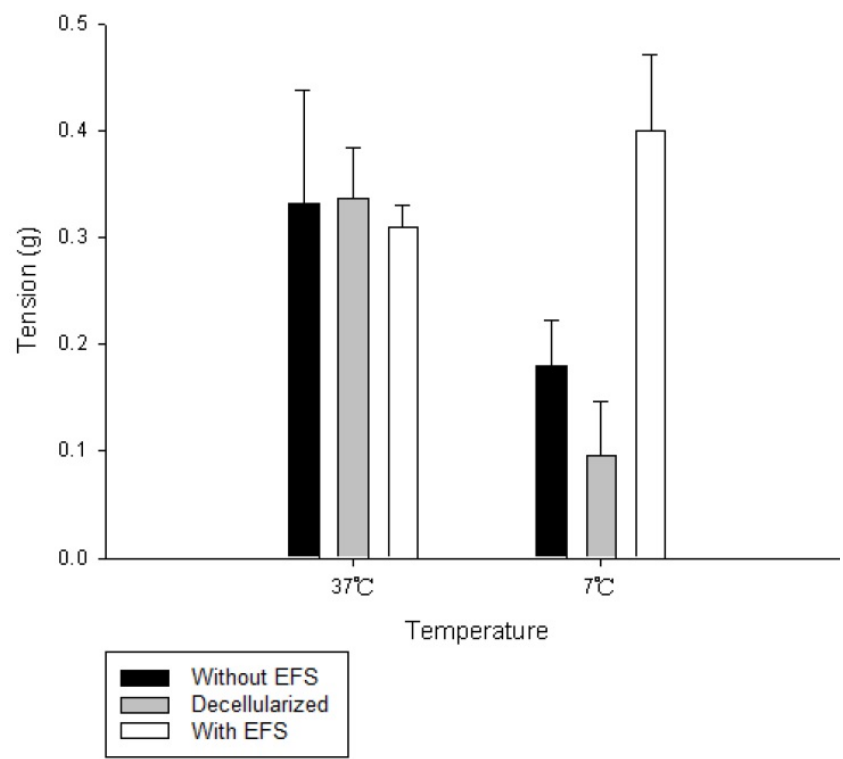

Figure 2. Average basal tension of tracheal strips at different temperatures. Comparing with the tracheal strip without EFS or decellularized tracheal strips, the basal tension of tracheal strips with EFS increased significantly between $7^{\circ} \mathrm{C}$ and $37^{\circ} \mathrm{C}$. EFS (electrical field stimulation).

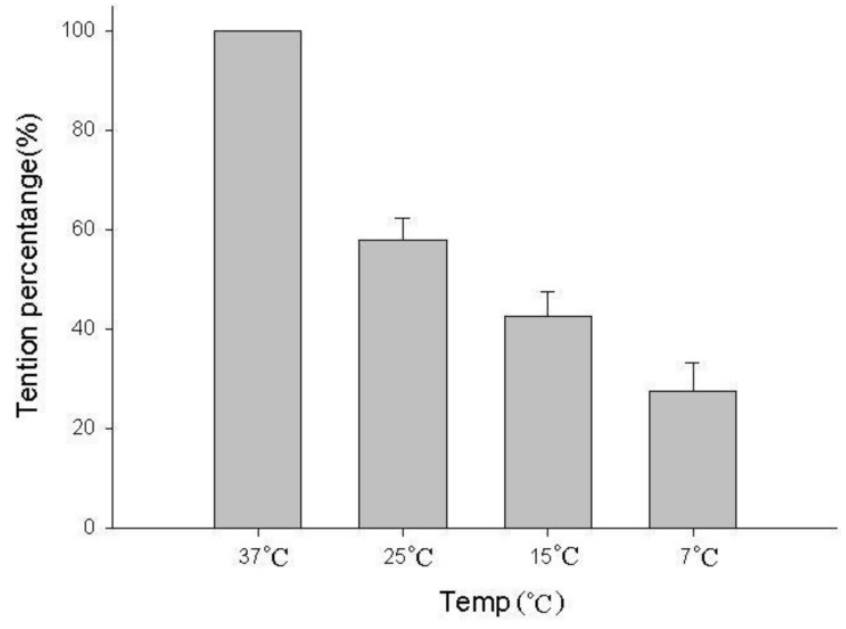

Figure 3. The basal tension of tracheal strips without EFS decreased significantly between $37^{\circ} \mathrm{C}, 25^{\circ} \mathrm{C}, 15^{\circ} \mathrm{C}$ and $7{ }^{\circ} \mathrm{C}$. The basal tension of strips at $25^{\circ} \mathrm{C}, 15^{\circ} \mathrm{C}$ and $7{ }^{\circ} \mathrm{C}$ are $57.8 \% \pm 4.3 \%, 42.5 \% \pm 4.9 \%$ and $27.5 \% \pm 5.6 \%$ of contraction respectively as compared with that at $37^{\circ} \mathrm{C}$ calculated as $100 \%$. EFS (electrical field stimulation). Results were mean $\pm S D(n=6)$.

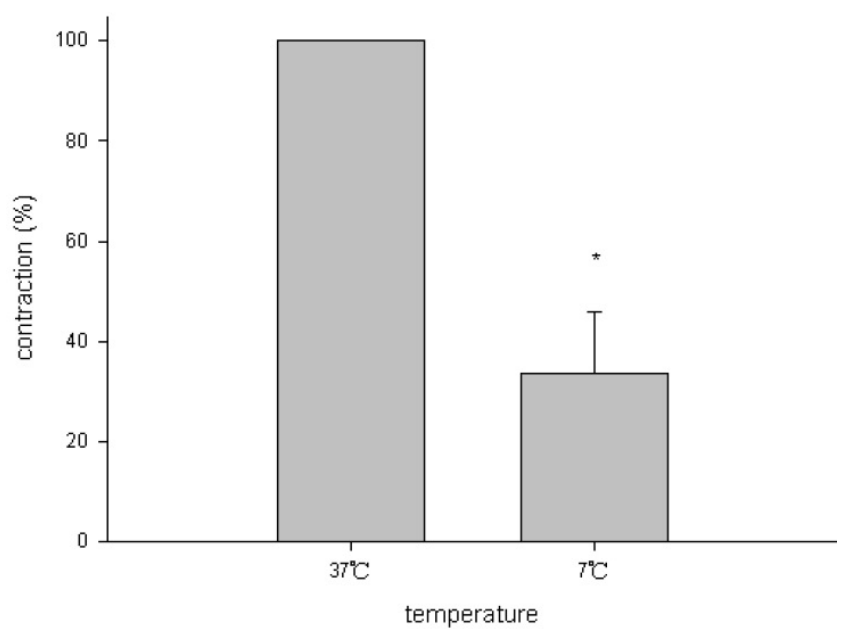

Figure 4. EFS-induced spike contraction of tracheal strips at different temperatures. The EFS-evoked tension peaks of the trachea was $100 \%$ and $35.0 \% \pm 12.8 \%$ of the control values at $37^{\circ} \mathrm{C}$ and $7^{\circ} \mathrm{C}$, respectively; indicating significant decrease in spike tension of tracheal strips between $7^{\circ} \mathrm{C}$ and $37^{\circ} \mathrm{C}$. EFS (electrical field stimulation). Results were mean $\pm S D(n=6)$.

\section{Acknowledgments}

This work was supported in part by the Taipei Medical University - Shuang Ho Hospital (106FRP-02).

\section{Ethical approval}

This study was approved by an animal experiment review board (LAC-2017-0036). All applicable international, national, and institutional guidelines for the care and use of animals were followed. 


\section{Conflict of Interest}

The authors have no conflicts to declare pertaining to this article.

\section{References}

1. Pleschka K. Control of tongue blood flow in regulation of heat loss in mammals. Rev Physiol Biochem Pharmacol 1984; 100:75-120.

2. Chu Y-H, Wu C-C, Kao C-H, et al. Low temperature decreased tension in isolated hypertrophic human nasal mucosa. Ame J Rhinol 2006; 20:84-6.

3. Mustafa SM, Pilcher CW, Williams KI. Cooling-induced contraction in ovine airways smooth muscle. Pharmacol Res 1999; 39:113-23.

4. Chiu F-H, Wang H-W. The evaluation of thioperamide effects using rat's trachea model. Clin Exp Otorhinolaryngol 2013; 6:1-6.

5. Wang H-W, Liu S-C, Chao P-Z, et al. Menthol inhibiting parasympathetic function of tracheal smooth muscle. Int J Med Sci 2016; 13: 923-8.

6. Schaner PJ, Martin ND, Tulenko TN, et al. Decellularized vein as a potential scaffold for vascular tissue engineering. J Vasc Surg 2004; 40:146-53.

7. Jongejan RC1, de Jongste JC, Raatgeep RC, et al. Effects of cooling on in vitro responses of human peripheral airways to inflammatory mediators and neurotransmitters. Agents Actions 1989; 26:73-4.

8. Ishii T, Shimo Y. Effect of cooling on ovalbumin-induced contraction of the tracheal muscle isolated from actively sensitized rat. Arch Int Pharmacodyn Ther 1987; 287:133-45.

9. Bratton DL, Tanaka DT, Grunstein MM. Effects of temperature on cholinergic contractility of rabbit airway smooth muscle. Ame J Phy 1987; 63:1933-41.

10. Khadadah M, Mustafa S, Elgazzar A. Effect of acute cold exposure on lung perfusion and tracheal smooth muscle contraction in rabbit. Eur J Appl Physiol 2011; 111:77-81.

11. González O, Santacana GE. Effect of low temperature on tracheal smooth muscle contractile and relaxing responses evoked by electrical field stimulation. P R Health Sci J 2001; 20:237-44

12. Cameron AR, Kirkpatrick CT. A study of excitatory neuromuscular transmission in the bovine trachea. J Physiol 1977; 270:733-45.

13. Ito $\mathrm{Y}$, Takeda K. Non-adrenergic inhibitory nerves and putative transmitters in the smooth muscle of cat trachea. J Physiol 1982; 330:497-511.

14. Postma DS, Kerstjens HA. Characteristics of airway hyperresponsiveness in asthma and chronic obstructive pulmonary disease. Am J Respir Crit Care Med 1998; 158:S187-92.

15. Giesbrecht GG, Younes M. Exercise- and cold-induced asthma. Can J Appl Physiol 1995; 20:300-14.

16. Tan X, Sun WD, Li JC, et al. Changes in pulmonary arteriole protein kinase calpha expression associated with supplemental L-arginine in broilers during cool temperature exposure. Br Poult Sci 2006; 47:230-6.

17. Zerpa $\mathrm{H}$, Berhane $\mathrm{Y}$, Woodcock $\mathrm{H}$, et al. Rho kinase activation and ROS production contributes to the cooling enhanced contraction in cutaneous equine digital veins. J Appl Physiol. 2010; 109:11-8. 